\title{
Asian Conferences on Analytical Chemistry
}

DOI: $10.1134 / \mathrm{S} 1061934810040015$

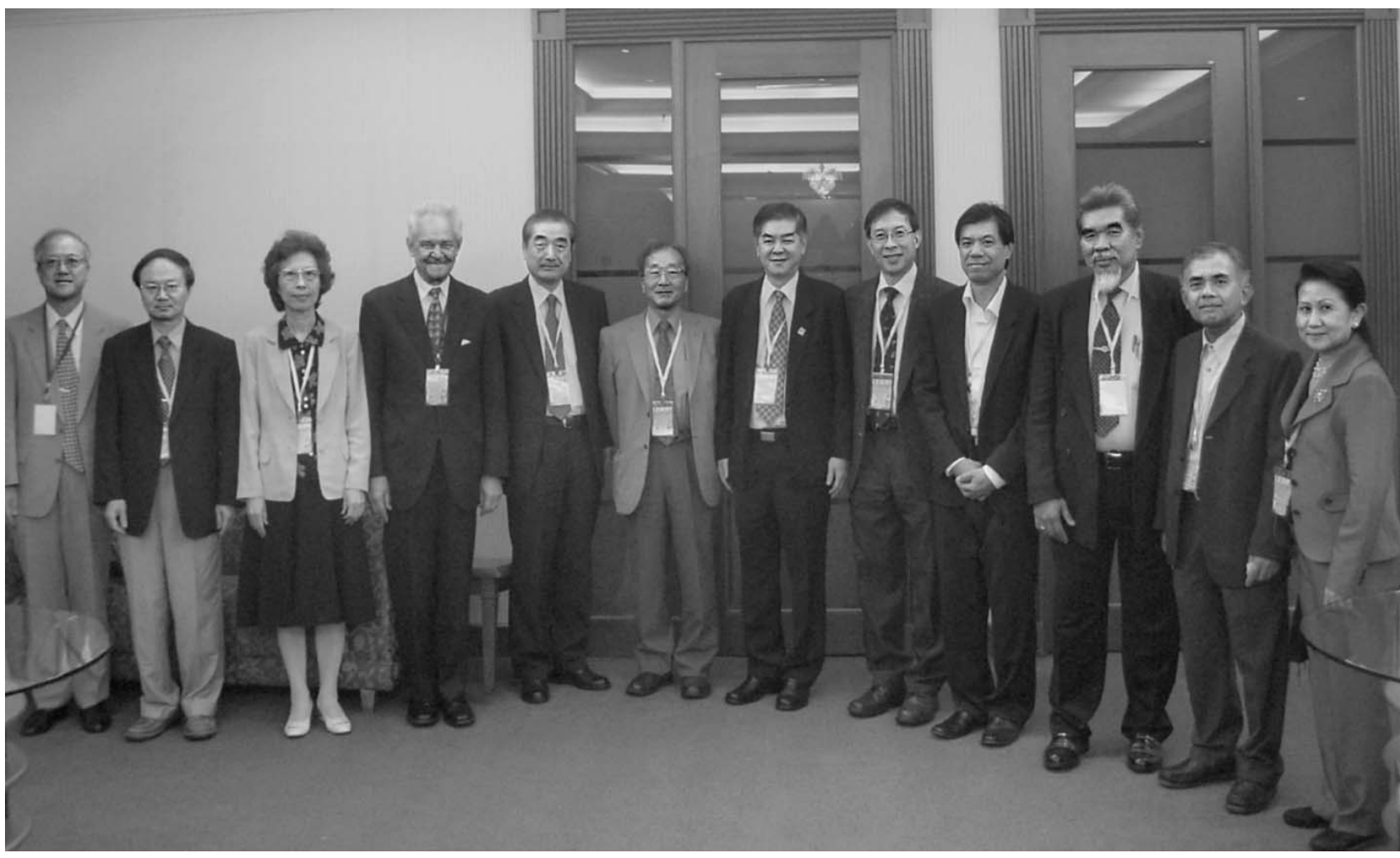

Members of the International Committee of the X Asian Conference on Analytical Chemistry, August 12, 2009. Academician Yu.A. Zolotov, Chair of the Scientific Council on Analytical Chemistry of the Russian Academy of Sciences is the fourth from the left.

These conferences are held biyearly in different Asian countries. This series of conferences was started in 1991, when the first conference, Asianalysis, organized within the limits of the International Congress on Analytical Sciences (ICAS), took place in Tokyo. Information about the other conferences is given in the table. The importance of these conferences is increasing; they are attended by a great number of scientists and experts.

The last conference Asianalysis took place on August 11-13, 2009 in Kuala Lumpur (Malaysia). It was attended by analysts from 32 countries (not only Asian) (see photo). There was a total of 532 presentations. National workshops and a big exhibition, LabAsia, were organized simultaneously. Many young researchers, teachers, instrument makers, etc., were among the participants of the conference and exhibition.

Asian conferences on analytical chemistry (Asianalysis)

\begin{tabular}{l|l|l|l}
\hline $\begin{array}{c}\text { Conference } \\
\text { number }\end{array}$ & Year & \multicolumn{1}{|c|}{ City } & $\begin{array}{c}\text { Country } \\
\text { (Territory) }\end{array}$ \\
\hline I & 1991 & Tokyo & Japan \\
II & 1993 & Changchun & China \\
III & 1995 & Seoul & South Korea \\
IV & 1997 & Fukuoka & Japan \\
V & 1999 & Xiamen & China \\
VI & 2001 & Tokyo & Japan \\
VII & 2003 & Hong Kong & China \\
VIII & 2005 & Taipei & Taiwan \\
IX & 2007 & South Island & South Korea \\
X & 2009 & Kuala Lumpur & Malaysia \\
\hline
\end{tabular}


At the conference, the participants discussed the proposal of the Japanese delegation to organize the Asian Analytical Chemistry Network. The proposal was basically approved, and the aims of the Network and the methods of its work were defined. One of the initial tasks is the "inventory" of experts of the Asian region; it is also assumed to make efforts towards the rapprochement of the character of and the means for teaching analytical chemistry in the countries of the region and to carry out other functions. The financial and organizational support for the network will be provided from the Japanese Society for the Promotion of Science (JSPS) and the Japanese Society for Analytical Chemistry.
It should be noted that many large conferences and exhibitions on analytical chemistry are held in Asian countries. Among the nearest ones are, for example, the 14th Asian Chemical Congress (Bangkok, Thailand, August 23-26, 2011) and the next International Congress on Analytical Sciences (Kyoto, Japan, May 22-26, 2011). The next conferences of the series, Asianalysis, will take place in 2011 in China and in 2013 in Japan.

Note that relatively many analysts work in Malaysia; they issue their journal, The Malaysian Journal of Analytical Sciences (ISSN 1394-2506).

Yu. A. Zolotov 